\title{
Cinzia Bevitori* and Jane Helen Johnson Risk and resilience in a changing climate: a diachronic analysis in the press across the globe
}

https://doi.org/10.1515/text-2020-0076

Received May 8, 2020; accepted January 11, 2022; published online January 31, 2022

\begin{abstract}
Building on our previous work investigating discourses of climateinduced mobility in the UK and US press, this paper addresses the overarching theme of environmental issues and the anthropocene by looking into representations of migration as adaptation in the context of climate change. In particular, drawing on corpus-assisted discourse analysis methodologies, the paper will focus on, and critically explore, meaning patterns of "risk" and "resilience" in a purpose-built diachronic corpus of quality newspapers from the Global North and the Global South between 2010 and 2017. Risk and resilience may in fact be regarded as the defining - though problematic - terms of our anthropogenic era. The investigation focuses on whether and how any significant discursive shifts may be identified in newspaper discourse across the globe and the extent to which the mainstream press reflects this problematicity. Our main findings show that not only is mention of risk more frequent in the Global North throughout than in the Global South media outlets, whereas the opposite is observed for resilience, but also that distinct meaning patterns emerge over time across the different areas of the world under investigation.
\end{abstract}

Keywords: adaptation; climate change-induced migration; corpus-assisted discourse studies; newspaper discourse; resilience; risk

\footnotetext{
*Corresponding author: Cinzia Bevitori, Department of Interpreting and Translation, Alma Mater University of Bologna, Corso Della Repubblica 136, 47121, Forli, Italy, E-mail: cinzia.bevitori@unibo.it. https://orcid.org/0000-0002-1288-4371 Jane Helen Johnson, Department of Modern Languages, Literatures and Cultures, Alma Mater University of Bologna, Bologna, Italy, E-mail: janehelen.johnson@unibo.it. https://orcid.org/ 0000-0001-5094-418X
}

ӘOpen Access. @ 2022 Cinzia Bevitori and Jane Helen Johnson, published by De Gruyter. $($ (c) BY work is licensed under the Creative Commons Attribution 4.0 International License. 


\section{Introduction}

This paper addresses the overarching theme of this Special Issue by presenting and discussing some findings of an ongoing research project on media representations of human mobility in the context of climate change over the last decade (Bevitori and Johnson 2017, 2018, 2021). In fact, while in the 1990s the Intergovernmental Panel on Climate Change (IPCC) warned about the potential "threatening short-term" effects of climate change on migration and resettlement in its first Assessment Report (IPCC 1990: 5-6), ${ }^{1}$ it was not until the adoption of the Cancun Agreement (COP16) in 2010 that the climate change-migration nexus emerged at the top of the international policy agenda. This was largely seen as a major turning point since countries for the first time formally acknowledged "climate change-induced migration, displacement and relocation" as major challenges the world would face in order to adapt to a warmer planet. ${ }^{2}$ Indeed, while the period from Cancun and Paris has been deemed a landmark period, contributing to "a distinct era of policy making" (Nash 2017), the strengthening of the climate change agenda in the aftermath of the Paris Agreement has also encouraged the emergence of systemic transformations that aimed to trigger new mitigation and adaptation practices. As widely recognized, in order to respond to climate change a two-pronged approach involving both practices is necessary; however, while the global goal on adaptation proposed in Article 7 of the Paris Agreement has yet to be reached, some progress may have been made with a proposal to implement a two-year programme to support countries in measuring and tracking adaptation, as announced at COP26 in Glasgow at the end of $2021 .^{3}$

A dual semantic dimension is seen to characterize the concept of adaptation in the institutionalized language of the IPCC. If, on the one hand, the notion assumes a degree of uncertainty about the possibility, or better the likelihood, that unpleasant events will occur, on the other hand, it also entails an opportunity, since

1 IPCC 1990, 5-9. The IPCC is an intergovernmental body set up by the World Meteorological Organization and the UN Environmental Programme in 1988 tasked with the assessment of the science related to climate change. See Bevitori 2010, 19. IPCC reports are available at: https://www.ipcc.ch/reports/.

2 See Art 14 (f) of the "Report of the Conference of the Parties in its 16th session, held in Cancun from 29 November to 10 December 2010”, p.5 - available at https://unfccc.int/resource/docs/ 2010/cop16/eng/07a01.pdf - accessed March 2018; see also Warner 2012, "Human migration and displacement in the context of adaptation to climate change: the Cancun Adaptation Framework and potential for future action”, Environment and Planning C: Government and Policy (2012). 3 See 'Section II Adaptation' in the draft text available at https://unfccc.int/documents/311096 (last accessed January 2022). 
the identification of a potential danger or threat may encourage the ability to activate coping strategies to avoid potential harm.

The present study will focus on meanings of risk which, with its associated baggage of resilience, are considered problematic (e.g. Clark and Bettini 2017). Risk and resilience may in fact be regarded as the defining terms of our anthropogenic era, carrying significant socio-political meanings and encoding different "social values and views of the world" (Stubbs 1996: 158), and, as such, may impact considerations of potential responses at governmental levels, as well as policy priorities (Hulme 2009). The study thus aims to further research by investigating the extent to which the mainstream press from different geopolitical areas of the world reflects this problematicity. For the purpose of our study, the paper is organized as follows. After this introductory section, we offer a selective review of the literature on risk and resilience, beginning with the definition of the two terms. Data and methodology will next be presented in Section 3, and the analysis and discussion of the findings will follow in Section 4, before concluding and suggesting ways forward.

\section{Risk and resilience: an overview}

Risk and resilience are two important categories in assessing the dynamics implicit in climate change adaptation, and both terms are characterized by distinct, multiple meanings.

Starting with the Oxford English Dictionary (henceforth OED), risk is defined as "(exposure to) the possibility of loss, injury, or other adverse or unwelcome circumstance; a chance or situation involving such a possibility”. The term has been used in a range of different disciplines in the economic, social, technical and ecological fields. For example, while from a classical economic perspective, risk is seen from a probabilistic perspective, distinguishing between risk and uncertainty (Knight 1921), or not unknowledgeable (Keynes 1937), scholars from different perspectives, following Beck (1992), regard risk as a social construction rather than probabilistic estimate. In other words, it is argued that it is the perception of risk more than the probability of something happening which can arouse the public imagination (see also Johnson 2014). From a sociological perspective, Giddens (1994) claimed that risks are not necessarily more significant, but they are thought to be so because we have become more aware of the possibility of risk than before. Threats have now become 'risks' - things over which humans could possibly exert control, instead of 'givens' (Lupton 1999: 74). The idea of agency playing a part in conceptualising risk is also picked up by Battistelli and Galantino (2019), who note that intentionality is a key factor, something that will be relevant for 
our own analysis. Much research over the years has focussed on risk discourses (see Zinn and Müller 2021 for an overview); however, due to space constraints an exhaustive review is beyond the scope of this work.

As regards environmental risk, as Latour (1987) has pointed out, its definition and evaluation is complex. Even in official climate change documentation, the conceptualisation and communication of risk is not always straightforward (Weingart et al. 2000). For instance, in the IPCC reports risk is defined as the "potential for consequences where something of value is at stake and where the outcome is uncertain" (Aven 2020: 1391), according to parameters of probability/likelihood, which are not adequately defined in the IPCC document; indeed, they seem to constitute a major problem for a correct understanding of climate change risk grounded on scientific evidence.

However, a distinction should be made between risk judgement and risk perception. According to Zinn and Taylor-Gooby (2006), potential catastrophes, such as environmental hazards linked to climate change, loom large in people's perception, and while there are advantages and disadvantages of using risk language in communicating environmental hazards (Painter 2013), the task of defining what constitutes a risk in this context is often left to the media, in their attempts to reconcile expert opinions with informing non-experts (Russo 2018: 20). Media in fact play a major role in today's world; indeed, they may be regarded as "critical links" between people's everyday lives, and the ways in which these are discussed at the boundaries between science, policy and public actors (Boykoff 2011: 2).

Turning to resilience, like risk, its definitions are also multi-layered and relate to different (disciplinary) contexts of use. In the OED the term is defined both as " $[t]$ he action or an act of rebounding or springing back; rebound" and as "[ $t$ ] he quality or fact of being able to recover quickly or easily from, or resist being affected by, a misfortune, shock, illness". While becoming increasingly frequent within diverse disciplines, the term has acquired specialised meanings. However, it was in the 1970s and particularly in the domain of ecology and environmental sciences that the term gained momentum (Methmann and Oels 2015), highlighting the adaptive capacity of the eco-system to positively "absorb perturbations" (Adger 2000: 349) and thus revert to a state of equilibrium. Following from the concept of "ecological resilience", in a similar vein, 'social resilience' hints at the ability of communities to withstand external shock or disturbances to their infrastructures. The link between ecological and social resilience advocated by Adger (2000) is relevant when seen from the perspective of climate change. In fact, the IPCC reports on climate change adaptation adopted this approach to resilience by defining the term as the "ability of a system and its component parts to anticipate, absorb, accommodate, or recover from the effects of a hazardous event in a timely and efficient manner” (IPCC 2012, 5). Likewise, the UN Secretary General's Panel 
of Global Sustainability in its 2012 report "Resilient People, Resilient Planet" (UN 2012) ${ }^{4}$ adopts an ecological approach (Bourbeau 2018: 11).

However, once in the domain of world politics and practices, the notion has since become highly controversial. According to Bettini (2017), in fact, discourses of resilience tend to reproduce the processes that underpin neoliberalism; i.e. "a transformative agenda whereby ecologically vulnerable populations - incidentally, the same at the margins of the globalised economy - are to become active adaptive agents" (p.36). While the critical perspective may certainly explain some dynamics inherent in the process of adaptation in climate-induced mobilities, we believe that a corpus-assisted approach may provide a methodological contribution in detecting some of the possible nuances of the term in this specialized domain of analysis, in the attempt to widen our perspective on the issue. It is the methodological approach that we will briefly discuss in the following section.

\section{Data and methodology}

For this study, the Climate Change \& Human Migration (CC \& HM) corpus was compiled to include a diversity of quality newspapers between 2010 and 2017. Newspaper articles appearing in four 'critical moments' coinciding with the Conferences of the Parties (COP) to the UNFCCC, namely Cancun (2010), Paris (2015), Marrakech (2016) and Bonn (2017), and their follow-up were selected and stored from six quality English-language newspapers from different geopolitical areas of the world, three from the Global North (GN) and three from the Global South (GS), in order to gain insight into media representations in different geopolitical contexts. These were, for the GN, The Guardian (GUA: UK), the New York Times (NYT: US), and The Australian (AUS: Australia) and, for the GS, The Nation (NTHAI: Thailand), The Daily Nation (DNAT: Kenya) and The Times of India (TOI: India).

The rationale for selection of these newspapers was based on a number of criteria such as wide circulation, location within representative areas of the GN and the GS, and availability via the Lexis-Nexis platform. In order to compile a specialized corpus on the interrelated issue of climate-induced migration, all articles containing the search words "climate" and "human mobility" or displac* or ${ }^{\star}$ migra $^{\star}$ or refugee ${ }^{\star 5}$ over the periods examined were accessed and stored. Articles were collected that were published over three consecutive months, including the

4 UN 2012, "Resilient people, resilient planet. A future worth choosing”. Available at https://en. unesco.org/system/files/GSP_Report_web_final.pdf (accessed November 2020).

5 Words within quotation marks "..." must appear as a single string, while the asterisk ${ }^{\star}$ is a wildcard representing any letter/s appearing in this position. 
winter months (October-November-December) in which the first significant COP was held in Cancun (November 2010), the period between this and the Paris conference (November 2015), the Marrakech conference (November 2016), and the Bonn conference (November 2017), as well as the three-month period in the spring (April-May-June) prior to each COP.

By way of example, Period I includes articles from April-May-June 2010 and October-November-December 2010. In this way we could focus easily on discourse in the months both before and after the key event in question, and thus better trace patterns of "signals and noise" (Boykoff 2011: 121). The articles were then checked manually for relevance, in that those articles containing fiction, or film reviews, etc. were removed. The total word count amounts to almost 700,000 running words. Table 1 shows the breakdown of data across newspapers and periods.

Due to the small size of some of the newspaper sub-corpora, an analysis of the cumulative GN and GS proved fruitful as a point of departure for further analysis. Looking at the data, some initial observations are in order. In fact, the GS subcorpus is only one fifth of the whole corpus. This finding, which may be surprising since the same criteria were used for gathering the articles, is clearly an indication of the degree of attention paid by media to aspects of climate-induced migration in the different outlets. However, in line with corpus linguistics methodology, the analysis will make use of relative frequencies, allowing figures to be compared across sub-corpora of different sizes.

Moreover, it should also be emphasized that while statistical measures are sensitive to the size of the corpus, methodologically and theoretically, the possibility of looking at data on different levels of details is one of the strengths of a corpus-assisted approach. The use of corpora to analyse features of discourse, in fact, has been an increasingly productive and dynamic field of study over the last two decades (Baker and McEnery 2015; Partington et al. 2013). Based on the

Table 1: Breakdown of running words per period and per newspaper in the CC\&HM corpus.

\begin{tabular}{|c|c|c|c|c|c|c|}
\hline \multirow[b]{2}{*}{ Text/period } & \multicolumn{3}{|c|}{ Global North (GN) } & \multicolumn{3}{|c|}{ Global South (GS) } \\
\hline & AUS & NYT & GUA & TOI & DNAT & NTHAI \\
\hline I & 8,712 & 25,064 & 13,486 & 4,769 & 0 & 8,996 \\
\hline II & 16,318 & 75,476 & 127,108 & 22,999 & 3,726 & 18,787 \\
\hline III & 8,005 & 104,056 & 54,266 & 12,044 & 7,368 & 7,212 \\
\hline IV & 4,694 & 104,384 & 36,051 & 17,191 & 6,459 & 6,497 \\
\hline \multirow[t]{2}{*}{ Totals } & 37,729 & $\begin{array}{r}308,980 \\
577,620\end{array}$ & 230,911 & 57,003 & $\begin{array}{c}17,553 \\
116,048\end{array}$ & 41,492 \\
\hline & \multicolumn{6}{|c|}{693,668} \\
\hline
\end{tabular}


combination of corpus linguistics techniques with critical discourse analysis, grounded within systemic functional linguistics (SFL) (Halliday and Matthiessen 2004; Thompson and Hunston 2006), our approach implies not only a crossfeeding interaction of quantitative and qualitative dimensions of investigation, but also, and perhaps more importantly, an interrelated set of top-down and bottomup procedures, involving a constant backwards and forwards movement, 'shunting' (Halliday 2002 [1961]: 45) between concordance, text, and the wider sociopolitical context. From this perspective, the analysis of discourse is strongly based on the assumption that discourse and society are linked in a mutually and constitutive way.

\section{Analysis}

\subsection{The frequency of RISK and RESILIEN- ${ }^{6}$}

Although analysing quantitative data is not the primary purpose of this paper, a look at their frequencies and distribution across individual newspapers in the corpus and across periods may provide warrant for a qualitative discussion of our findings. In this section, we will thus present a brief summary of the relative

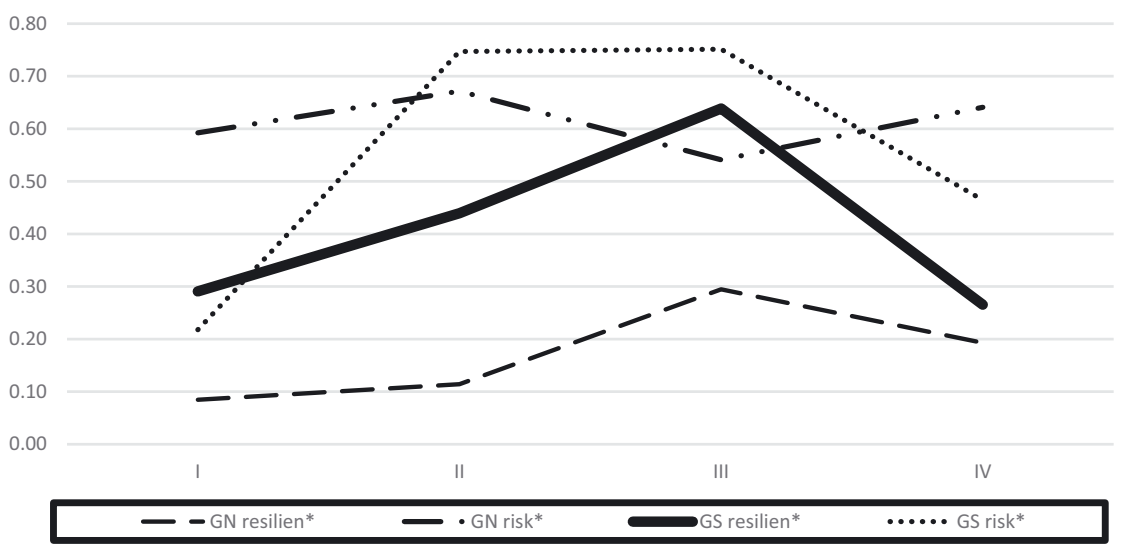

Figure 1: Relative frequencies of RISK and RESILIEN-across the GN and GS.

6 In the analysis, small capitals refer to lemmas, italics to word forms. 
frequencies of the queries RISK and RESILIEN- (including all word forms of the lemmas) expressed in the number of instances per 1000 running words.

Figure 1 shows the cumulative relative frequencies for RISK and RESILIEN-across the two areas.

\subsubsection{RISK}

The lemma RISk has a similar relative frequency, 0.6, in both the GN and the GS. For the sake of comparison, the relative frequency is 0.2 in a general newspaper corpus such as SiBol, ${ }^{7}$ suggesting that the topic of the CC\&HM corpus is more closely associated with risk. However, the distribution of the lemma across the periods in the different newspapers in the sub-corpora (see Figure 2) follows different trends. While the distribution of mentions of RISK in the GN shows little fluctuation over time, mentions in the GS rise from fairly insignificant in period I to much more marked in periods II and III, before dropping again.

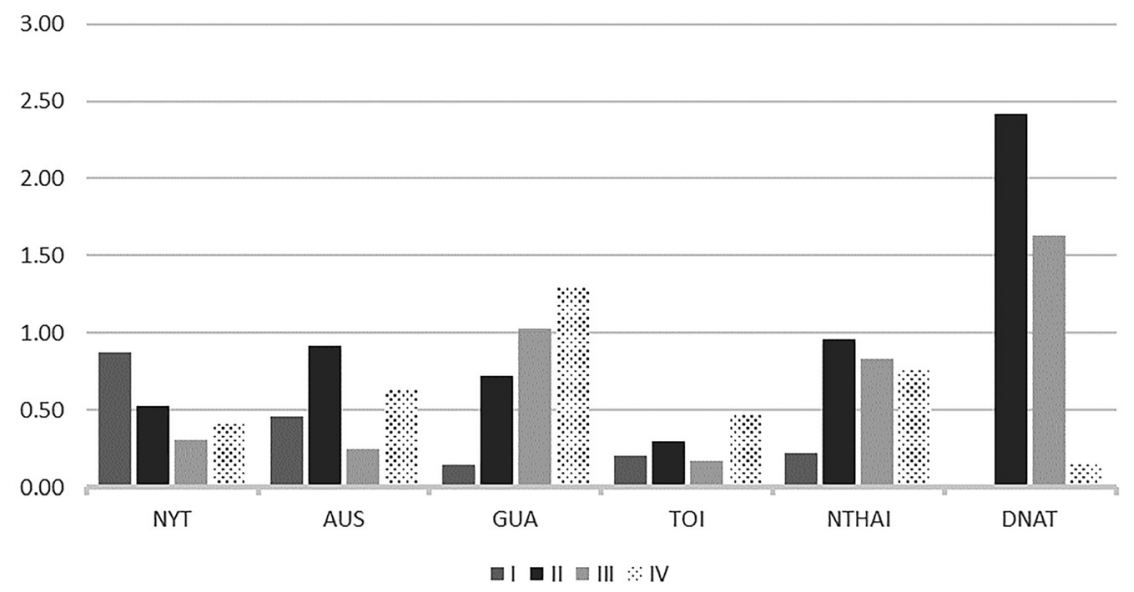

Figure 2: RISK across the newspapers and periods.

$7 \mathrm{SiBol}$ is the Siena-Bologna corpus of English broadsheet newspapers published between 1993 and 2013, available on SketchEngine, https://www.sketchengine.eu/ (accessed January 2022). 
Looking closer at the individual newspapers, The Guardian shows a steady increase in frequency of RISK, reaching a relative frequency of 1.3 in period IV, while the New York Times shows the opposite trend, with a relative frequency of 0.9 in period I, reflecting the media interest in the effects of the Deepwater Horizon oil spill in the spring of 2010, which then falls to 0.4 in period IV as interest in this particular event wanes. Looking instead at the GS, mentions of RISK in The Daily Nation are even more frequent relatively than in other newspapers in periods II and III, possibly due to the extreme weather events caused in the area the time by El Niño. The Times of India tends to mention RISK more frequently in period IV, where the articles feature reports of forthcoming plans for environmental risk assessment for the local area.

\subsubsection{ResiLIEN-}

Turning to the analysis of quantitative data of the lemma RESILIEN-, the breakdown across the newspapers and the periods is shown in Figure 3.

The lemma RESILIEN-is completely absent in period I in both the New York Times and The Times of India. Nor does it appear in the Times of India in period III, when The Guardian has the highest relative frequency of the word. The lemma only appears in periods III and IV in The Daily Nation, while The Australian has a strikingly frequent mention of the lemma in period IV, which may be explained in

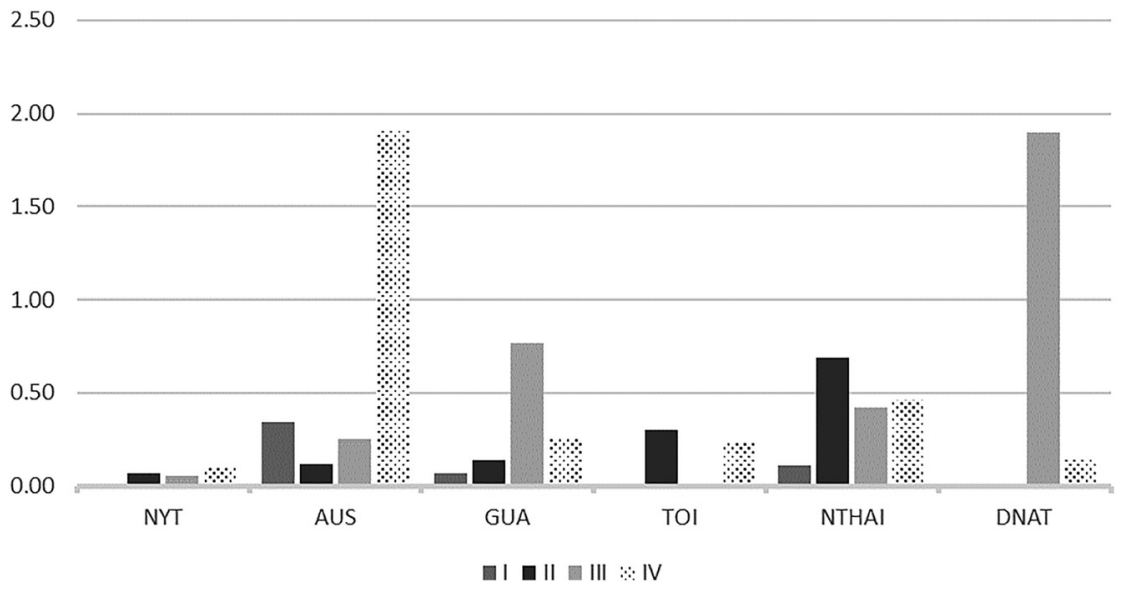

Figure 3: RESILIEN-across the newspapers and periods. 
terms of the large media coverage given to one of the severest cyclonic events to hit Australia in March 2017, and its consequences. Bearing in mind the quantitative results, we shall now move on to the qualitative analysis.

\subsection{Unpacking meanings of RISK and RESILIEN-}

While the quantitative analysis provides us with useful and relevant empirical data about levels of "signals and noise" (Boykoff 2011: 121), we need now to unpack the meanings of these terms in order to investigate what and how discourses of risk and resilience are represented in the corpus. Media are, in fact, not simply a mirror of reality, but help to shape this reality. As noted in Section 2, although the relationship between policy-making practices, media communication, attitudes and behaviour is far from straightforward, media representations play a critical role in shaping public understanding and perception of science, policy and institutional actors (Bevitori 2014; Boykoff 2011; Russo 2018). Therefore, a qualitative analysis of the selected lemma and their recurring patterns will be undertaken in order to gain a clearer picture of how the terms are used, and the kinds of meanings they realize.

\subsubsection{RISK}

As described above, the lemma RISk has been examined from different perspectives. Taking risk as a social construction and not a 'given', in certain fields descriptions of risks are closely connected with assessing the possibility or likelihood that something will happen. It is interesting therefore to examine in the context of our study the extent to which media outlets present risks as 'inevitable' or created by humans. We will therefore compare any differences and similarities diachronically over the four significant periods, beginning with the most frequent word form of RISK in our corpus, the noun form, found in $88 \%$ of occurrences.

The top ten lexical words occurring within a limited word span with risk as noun in the reference corpus SiBol almost exclusively refer to the semantic domain of health (especially cancer), reflecting the wider concerns of the general population. While most of the frequent qualifiers of the degree of risk, or intensifiers such as serious, high, great, or big are shared across both SiBol and the CC\&HM corpus, catastrophic (GS) and imminent (GN) instead do not appear as top collocates of risk in SiBol but suggest the urgency, negativity and massive scale of climate change risk, in line also with Russo's (2018: 99) findings.

As regards types of risk, in the GN these include climate change, flood, security, strategic and financial. Occurrences of security risks are mainly found in periods II and III, coinciding temporally with the UN Security Council's declaration that 
climate change was a security issue (Bevitori and Johnson 2017; Boas 2015). While $20 \%$ of these refer to global security (including food security), all the others refer to national security, in the sense of their own nation (cf. Australia and the US). It is worth noting that while no example in the GN places the existence of climate change-related security risks in doubt, some suggest that they are underestimated or not properly understood, or certainly need to be addressed, as in example (1). ${ }^{8}$

1) We have to work with the international community to make Australians, and citizens of all nations, safer from both conflict and the impacts of climate change, knowing that these issues and our futures are intertwined. If we are serious about addressing the considerable strategic risks to our national security we need to join other advanced economies and dramatically increase our ambition on tackling climate change, and soon. AUS II 09/12/2015

As Russo (2018: 76) also notes, the positive value of security (keeping people safe) here contrasts with the negative, unspecified description of 'strategic risk' to security. On the subject of security, slightly earlier in period II, albeit in a different newspaper, The Guardian, an interesting overlap between risk and threat is identifiable:

2) Global warming 'ultimate threat multiplier' posing serious risk to world security, says report urging governments not to see it simply as a climate issue. Tackling climate change risks must become a top foreign policy priority if the world is to combat the global security threat it poses in the 21st century, according to a new study commissioned by the G7 countries. GUA II 24/06/2015

Climate change is here described both as a risk and a threat to world/global security. It is worth noting that the near-synonym threat collocates much more frequently than risk (60 times) with security (mainly in The Guardian), and 5 times with conflict. In security discourses, security threats are defined as more concrete and probable than security risks. Though the words are often used interchangeably, it has been suggested that some sort of agent is implied with the choice of the word threat - though the agent is not necessarily human - whereas agency is absent when the word risk is used (Battistelli and Galantino 2019). Placing the onus on the public to do something about the situation rather than framing potential harms as givens could be a winning strategy in climate change action, although security language does not necessarily help to increase the urgency of climate action (Warner and Boas 2017). We may however consider the overlapping usage of

8 Words and phrases in bold in the quotations are referred to in the analysis. 
risk and threat to be part of the expanding discourse of security. In addition, their almost interchangeable use, as in (2), might be evidence of a pervading 'instability' in language choices (Russo 2018: 141).

Security risk in the GN is typically accompanied by co-text with negative connotations, as in the emboldened words in example (3):

3) In 2015, a UK foreign office report made a stark assessment of the dangers posed by unchecked global warming, including very large risks to global food security, increased risk of terrorism as states fail, and unprecedented migration that would overwhelm international assistance. GUA III 01/12/2016

The idea that climate-change security might be threatened by conflict is present in the GN media, as in example (4). Security here is extended to include energy security and connection between conflict, security, and access to energy, which 'should not be underestimated', as clearly set out here:

4) We need a "global clean energy community" to free us from dependence on fossil fuels and the related risks of conflict. Reducing carbon intensity improves security - energy security and security in general - as it equalizes access to energy. A country that develops its own solar- or windenergy production takes nothing from anyone: The light and wind that it uses are not only renewable; they belong to all. We should not underestimate the major contribution this could make to peace and security. NYT II 25/04/2015

Like security, risk and conflict in the GN sub-corpus almost always co-occur in periods II and III.

In the GS, the top collocates premodifying the noun risk refer to degree of intensity, similarly to the GN (catastrophic, significant, high and big), as well as the type of risk (earthquake, geopolitical, societal, fire, disaster). Frequent types of risk can also be identified in the phrase risk(s) of: here we find flooding and conflict, as well as risks connected with migration and displacement. Unlike the occurrences in the GN, they often refer to present rather than potential situations, with suggestions and advice from experts of what should be done, as in examples (5) and (6) below. 'Expert knowledge' is represented in 73\% of the GS media's references to risk, though these are mainly clustered in period I and period II, In example (5), expert opinion is cited as justification for government action, clearly signalled by the phrase it's time for the government to.

5) Experts say that while it was heartening to notice the massive response of the general public to calls for aid in Chennai, it's time for the government 


\section{also to put its act together and bring about some legislation for environmental refugees. TOI II 08/12/2015}

6) Impoverished people in the world are already being hurt by heat waves, drought and flooding, because they are both more dependent on the land and lack public services. NTHAI II 02/12/2015

Note the simple conjunction 'because' in example (6), providing a clear connection to explain how climate change risks can affect people. This structure is typical of the GS media, instrumental in offering expert opinions clearly.

Security risks also appear in the GS media, but, unlike the GN, as noted also by Schäfer et al. (2016), they relate particularly to water and food security:

7) Water sources are drying up due to lack of ground water recharge in summers, the study found. Decreased precipitation in the post-monsoon season has been observed. The trend is projected to continue in future, posing a particular risk to villages, which have no irrigation such as Karni Guth, Chameli and Kantari (Uttarkashi). Jha said, "Implementing water storage and conservation options are required to increase resilience to climate change.” TOI IV 05/06/2017

Reference to water and food security is practically absent in the GN. However, not only does the GS media talk about food and water security, something their own readers will relate to, but also as regards the impact on the world as a whole. While security and conflict risks are frequent only in periods II and III of the GN subcorpus, flooding - and the related risks of coastal erosion and sea level rise - is the most frequent type of risk mentioned throughout the same sub-corpus. References are often made to future or potential flood risks, with the New York Times focussing particularly on flooding affecting the US. The Guardian instead tends to focus more on other nations' relationship with climate change, apart from the mentions of flooding in the UK in Period III, coinciding with the Government's report on flooding damage in the UK.

In the earliest period of the GS sub-corpus, even present risks are considered rather hypothetical, to such a degree that on one occasion, one expert's description of flood risks is contrasted by the local official's account:

8) Currently, the administration finds it difficult to even conceive of such changes. "We wouldn't know unless we made a study of it," said an official in the Chennai Corporation. "Based on our data from previous flooding and tsunami, it may seem that low- lying areas like Vysarpadi, Foreshore Estate, Kotturpuram, Tiruvottriyur and Ennore High Road maybe at a risk. 
However, the breakwater constructed along the coast for the harbour may protect the city from the devastating consequences of any rough weather that occurs after the sea level rise.” TOI I 23/11/2010

In example (8), the repeated use of operators with low epistemic modality (may seem, may be) suggests a high degree of uncertainty, and the official's view of the scenario as almost impossible to contemplate is exacerbated by the reporter's decision to use direct quotation here. This could be a way to distance him/herself from the proposition rather than present it as fact (c.f. Bevitori 2011; Russo 2018: 103). The message to the readers is certainly unclear.

Flooding from rising sea level, ice melt and storms is certainly a particularly 'visible' risk. This might explain why it makes up the largest single category of risks cited in the corpus, with 20\% falling into this group. As Bevitori (2011: 371) suggests, an appeal to the visual perception of future catastrophic events is effective in persuading the public about climate change risks.

Instead, what is perhaps surprisingly absent in the CC\&HM corpus is mass migration and displacement as a climate change risk, noted elsewhere as construing an 'unbalanced' climate change narrative often perpetrated in the media (Bettini 2013). It appears just four times in the GN, and as many times in the GS, from which comes example (9), in which a lack of food may also lead to greater risk to security, as well as reminding us that climate change acts as a threat multiplier.

9) If the drought continues into this month, hundreds of thousands of people risk losing everything. Most of these people depend on livestock or crops for food and cash. If the rains fail once more, they face catastrophe. On top of acute food insecurity, continuing drought could have a negative impact on broader security - strengthening Islamist jihadists who are currently on the back foot - and increase the flow of migrants to Europe and elsewhere. DNAT III 7/4/2016

Left collocates of the noun form often include co-occurring material processes also found in SiBol (pose, run, carry, take, face, etc.). However, there is a slight difference between SiBol and CC\&HM, and between the GN and GS, as regards other frequent processes, in that risk in the GN is often preceded by the mental processes understand and realise. This might initially suggest that a cognitive effort to grapple with the situation is being made in the GN media but not in the GS media. However, a closer reading shows that, while the cognitive effort is recognised as important, people are still not making it, or understanding and full realisation is claimed to be the prerogative of experts, as in example (10):

10) "There have been storms in the past that were probably as big as Sandy, such as in 1821, but you would be worried if these events become more frequent," said Ning Lin, lead author and assistant professor of civil and 
environmental engineering at Princeton. Sandy was a wake-up call... Many other places may not even realize the risk, which is worrisome. GUA III $11 / 10 / 2016$

This shows a constant tension between providing expert knowledge and being able to transmit it appropriately to the general public, which is more consciously expressed in the GN. Instead, the GS relies on quoting expert opinions tout court, including experts who might be academics but also international authors or political figures. As mentioned above, most occurrences of risk in the GS appear as part of expert opinions, while other mentions are related to the tangible, local, present and imminent effects of climate change risk, thus embodying the news values of proximity, immediacy and negativity (Bednarek and Caple 2014; Galtung and Ruge 1965). A description of the obvious and recent local effects of climate change is useful not only to provide concrete evidence but also to get the public to do something about it, since it is not knowledge per se that counts in determining support of policy-making, but "[i]t will do so only if existence beliefs, attitudes, and beliefs about human responsibility are in place to permit the necessary reasoning steps to unfold" (Krosnick et al. 2006: 37). Such attitudes may be influenced by interventions as in example (11) from the writer Amitav Ghosh interviewed in The Times of India:

11) 'It's not that we don't have expertise, we have good reporters. But what is very striking in India is the absence of any broad public engagement with climate change," Ghosh added. TOI II 03/12/2015

Ghosh's authority to be quoted here comes not from his internationally acclaimed novels so much as his non-fiction work (Ghosh 2016) on climate change and literature.

\subsubsection{ResiLIEN-}

We will now delve deeper into the patterns of RESILIEN-. In fact, while the quantitative analysis demonstrates that this lexeme, in contrast to RISK, has a higher relative frequency in the mainstream press in the GS than the GN, looking at the data from a diachronic perspective shows that contextual knowledge is needed in order to gain insights into discourses of the different newspapers in the corpus. Some of the interrelated questions we will try to answer are then necessarily embedded into more qualitative processes of interpretation. First of all, a main point concerns the extent to which 'discourses of resilience' in the GN and GS mainstream press are shared or, conversely, unshared over time, and whether any similarities or differences emerge between the newspapers' positioning towards 
the issue at stake. While the comparative analysis shows some similarities, a significant number of differences emerge.

The most frequent word form of the lemma across both sub-corpora and across individual newspapers, overall with $74 \%$ of occurrences, is the noun form. However, while nominalizations are less explicit in terms of participant roles (Halliday and Matthiessen 2004), some functional elements, such as prepositions within the nominal group, can express complex transitivity, causal and relational properties between constituents. In fact, the most frequent grammatical colligates of the noun are the prepositions to and of. The latter is a generalized marker specifying or qualifying the term (e.g. the resilience of the islands), while the former (the preposition to) identifies the disturbing or disruptive entity; here climaterelated risks or effects. A preliminary analysis of the words typically co-occurring with the noun phrase 'the resilience of' in the GN shows that countries, cities and communities are the most frequent collocates occurring roughly $20 \%$ of times to the right of the node. Instead, left-hand collocates typically point to material processes realized by verbs such as build, improve, develop, strengthen (30\% of all instances), as well as words related to the semantic field of 'risk and disaster'. A more systematic look at the most frequent co-selection patterns, i.e. building or developing the resilience of the countries reveals that the Goal, i.e. countries, is construed as the beneficiary of the material process of helping, or enabling, to build or develop resilience, of which the following examples provide an illustration:

12) The climate conference provides a critical opportunity to galvanise the support of financial institutions, development partners and bilateral and multilateral partnerships, to enable vulnerable countries to develop resilience to climate change. GUA II 03/12/2015

13) The update also reaffirmed Mr Turnbull's commitment to negotiators at the Paris climate conference to ensure at least \$1 billion of Australia's foreign aid budget was spent on helping vulnerable countries reduce their emissions and build resilience to the impacts of global warming. AUS II $16 / 12 / 2015$

It is worth pointing out that the entity, as defined above, is also frequently categorized through adjectives or classifiers (e.g. climate resilience) in our sub-corpus:

14) Australia had spent more than $\$ 50 \mathrm{~m}$ in climate resilience projects in the Pacific and contributed another $\$ 200 \mathrm{~m}$ to the Green Climate Fund. GUA II $30 / 11 / 2015$

As the above examples show, the typical co-selection patterns reveal a semantic set of words related to economic or financial assistance (aid, budget, money, fund), 
especially by institutional actors both at the supranational and national levels. However, the diachronic analysis also reveals that the majority of the instances are not only circumscribed in time, mostly immediately preceding and following the negotiations in Paris in 2015 (winter II and spring III) but also circumscribed in space, focussing in particular on the vulnerability of countries in the GS, especially the Pacific islands and some African regions (15).

15) In humanitarian and developmental circles, there is much talk about the importance of building resilience to protect communities on the frontline of weather shocks. For farmers in Somalia, it can be something as simple as sharing long-term weather forecasts. GUA III 17/06/2016

Another observation concerns the individual newspapers in the corpus; indeed, one of the advantages of working with specialized, relatively small corpora is the opportunity to better handle the material for closer analytical purposes by 'shunting' between concordance lines and the enlarged co-text and context. While most of the instances show that The Guardian and The Australian tend to frame the issue from an international or global perspective, the New York Times also tends, similarly to risk as analysed above (Section 4.2.1), to typically represent resilience as an issue of national and domestic security (example 16), thus privileging news values of proximity, and domestic interests:

16) "While there remains some debate about the cause of climate change, there has been a documented change in weather patterns over time in Wisconsin," the report noted, adding later, "Climate resilience is a state and national priority.” NYT IV 05/11/2017

As regards the co-selected noun city/ies, as well as the adjective urban, some differences emerge pointing to more nuanced meanings of resilience. Here a new meaning of what can be regarded as 'social resilience' is seen to emerge from period III and period IV, entailing a notion of 'adaptability', more than 'adaptation', geared towards a transformative capacity of urban cities and infrastructures to manage risk in the long run (examples 17 and 18):

17) In Vejle, protecting against climate, economic and social shocks takes on a very human form. Underlying all aspects of its resilience strategy is the mantra of "co-creation", a bottom-up meets top-down approach that calls for collaboration between citizens and the municipality. GUA III 19/05/2016 
18) Prosperity will ultimately belong to cities and nations around the world that find ways to capitalize on strategies of resilience against the inevitable impact of climate change. NYT IV 09/04/2017

The occurrence of these meaning patterns then suggests a semantic shift towards discourses of 'social resilience' as a transformative, collaborative, and certainly more dynamic developmental process; i.e. a pro-active, and even transformative, aptitude to prevent hazardous events (see also Keck and Sakdapolrak 2013: 10). A comparison between the two sub-corpora shows that, in spite of similar collocational behaviour as regards the material processes build/building, increase, enhance raise and strengthen, unlike in the GN sub-corpus, the affected entity in the GS is almost exclusively realized by community/ies and people; in contrast, urban areas are virtually absent:

19) Building community resilience through active identification and prevention of risks, capacity-building of civil society and local administration, and improved preparedness, relying on available lowcost techniques, are an imperative, not luxury, for these Himalayan countries. NTHAI II 05/06/2015

20) It means building resilience and strengthening the livelihoods of people in ways that not only drive recovery from war, disease, floods, and other shocks, but also help to reduce the impact of these crises and, where possible, prevent them from taking place altogether. DNAT III 03/06/2016

However, the number of instances is perhaps too small to make any generalization; in fact, the data reveals that almost $84 \%$ of all instances arise in periods II and III; the former in The Nation Thailand, the latter in the Kenyan Daily Nation, as in examples (19) and (20). In the following period, and particularly in The Times of India, discourses in the GS seem to revolve around the semantic domain of technological innovation. Interestingly, in a detailed keywords analysis ${ }^{9}$ of the GS subcorpus compared to the GN, the word 'technology' emerges as a top ranking word, occurring 51 times in the GS (0.05) compared to only one mention in the GN. Typical associations with meaning patterns of RESILIEN-here point towards technological innovation, efficient energy and, particularly, decarbonisation:

21) In this context, the leaders underlined the importance of enhancing IndoFrench cooperation on joint research and development and technology innovation as well as diffusion of clean energy and efficiency solutions that

9 Keywords are words occurring more frequently than would be expected in one corpus when compared with another. 
will help in transitioning towards a climate resilient and low carbon economy. TOI II 11/04/2015

This emerges more clearly when we look at instances of the adjective resilient. Although less frequent overall, representing 30\% of all occurrences, an analysis of the adjective suggests some interesting similarities and differences. In fact, as shown in the previous examples, unlike in the GN, the patterns of co-occurrence of resilient in the GS show a preference for the qualifiers low and carbon (6 occurrences). Again, almost all the instances occur in period II, where a commitment at a more governance level to advancing and promoting development and growth tends to arise.

\section{Discussion and conclusions}

As one of the most pressing political challenges of our times, climate change has increasingly become a crucial site for the 'struggle over meaning' across different domains. The aim of this paper was to explore the meanings of RISK and RESILIEN-as two interrelated dimensions in our anthropocene era construing climate adaptation within newspaper discourse across the Global North and the Global South. In fact, the use of these two categories has been instrumental in the design and investigation of our specialized CC\&HM corpus. The corpus has enabled us to investigate the dynamics implicit in climate change adaptation by examining risk and resilience across key periods in climate change policy making in the media of two distinct geographical areas. Methodologically, the combination of corpusassisted discourse studies and systemic functional linguistics has proved a valuable way to uncover specific patterns of meanings which would otherwise have been difficult to access.

In particular, our findings suggest that risk is more frequently mentioned in the GN throughout the periods than in the GS, while the opposite is true for resilience, which is more prominent in the GS and particularly significant in the GS in period II. Moreover, in the GS, risk tends to be related to expert opinion, particularly in periods I and II, thus providing a basis for justifying why and what measures should be taken and providing supporting arguments for action. In the same period in the GS, there is emphasis on a commitment at governance level towards promoting resilience, with technological innovation, energy and decarbonisation cited as contributing to the construction of resilience particularly in The Times of India. As regards resilience, there is a wider focus in the GN on countries of the GS, mainly in a limited period of time between winter II and spring III. 
Instead the GS media, with its tendency to refer to locally relevant situations, placed the emphasis on resilience for communities. Perhaps unsurprisingly, The Guardian is the GN newspaper with the most international perspective, as regards both resilience and risk. The Australian too is concerned with resilience in a global perspective, while resilience in relation to national security is at the forefront in this respect in the New York Times. Security risk in general, as well as risk of conflict, are issues emerging as significant in the GN, particularly in period II between the Paris and Marrakech COPs, which is evidence of an increasing securitisation of media reporting of climate change in Western sources in this period. We also find a constant overlap between what is defined as risk and what as threat. Food and water security risks are instead mentioned more frequently in the GS, again understandably related to local situations.

A focus on social resilience gradually emerges in the GN press, towards the later periods III and IV, with resilience here seen as 'adaptability', referring to the capacity of urban centres and infrastructures to handle uncertain risks, thus creating a proactive collaborative dynamic. The risks of migration and displacement are unpredictably absent throughout. Finally, while financial risk is typically construed as a type of climate change risk in the GN, particularly in Period II, this is practically absent in the GS outlets. Here the focus on the need for divestment from fossil fuel industries, and much soul-searching, may hint at a Western problem about the need to do so.

Though space prevents us in this paper to do more than uncover a part of the nuances involved, observations and insights have emerged which will provide a basis for further study. Areas for future research could include further investigating the implications of risk together with its near-synonyms as well as looking closer at the ongoing development of discourses of resilience and adaptation, by expanding the corpus both diachronically and synchronically.

\section{References}

Adger, Neil W. 2000. Social and ecological resilience: Are they related? Progress in Human Geography 24(3). 347-364.

Aven, Terje. 2020. Climate change risk - what is it and how should it be expressed? Journal of Risk Research 23(11). 1387-1404.

Paul Baker \& Tony McEnery (eds.). 2015. Corpora and discourse studies. Basingstoke: Palgrave. Battistelli, Fabrizio \& Maria Grazia Galantino. 2019. Dangers, risks and threats: An alternative conceptualisation to the catch-all concept of risk. Current Sociology 67(1). 64-78.

Beck, Ulrich. 1992. The risk society: Towards a new modernity. London: Sage. 
Bednarek, Monika \& Helen Caple. 2014. Why do news values matter? Towards a new methodological framework for analysing news discourse in critical discourse analysis and beyond. Discourse \& Society 25(2). 135-158.

Bettini, Giovanni. 2013. (In)convenient convergences: “Climate refugees”, apocalyptic discourses and the depoliticization of the debate on climate-induced migration. In Chris Methmann, Delf Rothe \& Benjamin Stephan (eds.), De-)constructing the greenhouse: Interpretive approaches to global climate governance, 122-136. London: Routledge.

Bettini, Giovanni. 2017. Where next? Climate change, migration, and the (bio)politics of adaptation. Global Policy 8(1). 33-38.

Bevitori, Cinzia. 2010. Representations of climate change. News and opinion discourse in UK and US quality press: A corpus-assisted discourse study. Bologna: Bononia University Press.

Bevitori, Cinzia. 2011. “Imagine, if you will..." Reader positioning on climate change in US op-ed Articles. In Gabriella Di Martino, Linda Lombardo \& Stefania Nuccorini (eds.), Challenges for the 21st Century: Dilemmas, ambiguities, directions, 367-376. Rome: Edizioni Q.

Bevitori, Cinzia. 2014. Values, assumptions and beliefs in British newspaper editorial coverage of climate change. In Chris Hart \& Piotr Cap (eds.), Contemporary critical discourse studies, 623-625. London: Bloomsbury Academic.

Bevitori, Cinzia \& Jane Helen Johnson. 2021. Moving or staying? Exploring im/mobility in the context of climate change. In Paper presented at the 30th European Systemic Functional Linguistics Conference, "Social Semiotics and Social Justice"15-17 September. University of Sheffield.

Bevitori, Cinzia \& Jane Helen Johnson. 2017. Human mobility and climate change at the crossroad: A diachronic corpus-assisted discourse analysis of the nexus in UK and US newspaper discourse. In Katherine E. Russo \& Wodak Ruth (eds.), The representation of 'exceptional migrants' in media discourse: The case of climate-induced migration. Special Issue of Anglistica AION an Interdisciplinary Journal, vol. 21, 1-19.

Bevitori, Cinzia \& Jane Helen Johnson. 2018. Patterns of movement, patterns of meaning: Exploring the climate-migration nexus in UK and US press discourse A diachronic corpusassisted discourse analytical approach. In Paper presented at the International Conference on Corpus Approaches to Discourse Analysis Across Disciplines, 4-6 July. University of Aalborg.

Boas, Ingrid. 2015. Climate migration and security. Securitisation as a strategy in climate change politics. New York: Routledge.

Bourbeau, Philippe. 2018. A genealogy of resilience. International Political Sociology 12(1). 19-35.

Boykoff, Michael T. 2011. Who speaks for the climate? Making sense of media reporting on climate change. Cambridge: Cambridge University Press.

Clark, Nigel \& Giovanni Bettini. 2017. 'Floods' of migrants, flows of care: Between climate displacement and global care chains. In Natalie Gill, Vicky Singleton \& Claire Waterton (eds.), The sociological review monographs special issue: Care and policy practices, vol. 65, 36-54.

Galtung, Johan \& Mari H. Ruge. 1965. The structure of foreign news. Journal of Peace Research 2(1). 64-90.

Geoff Thompson \& Susan Hunston (eds.). 2006. System and corpus: Exploring connections. London: Arnold. 
Ghosh, Amitav. 2016. The Great Derangement: Climate Change and the Unthinkable. Chicago: University of Chicago Press.

Giddens, Anthony. 1994. Living in a post-traditional society. In Ulrich Beck, Anthony Giddens \& Lash Scott (eds.), Reflexive modernisation: Politics, tradition and aesthetics in the modern social order, 56-109. Cambridge: Polity Press.

Halliday, Michael A. K. 2002 [1961]. Categories of the theory of grammar. In Jonathan J. Webster (ed.), On Grammar, vol. 1 in the collected works of M.A.K. Halliday, 37-94. London: Continuum.

Halliday, Michael A. K. \& Christian M. I. M. Matthiessen. 2004. An introduction to functional grammar, 3rd edn. London: Arnold.

Hulme, Michael. 2009. Why we disagree about climate change: Understanding controversy, inaction, and opportunity. Cambridge: Cambridge University Press.

Johnson, Jane Helen. 2014. Family in the UK - risks, threats and dangers: A modern diachronic corpus-assisted study across two genres. In Maurizio Gotti, S Davide \& Giannoni (eds.), Corpus analysis for descriptive and pedagogic purposes: ESP perspectives, 263-285. Peter Lang: Bern.

Keck, Markus \& Patrick Sakdapolrak. 2013. What is social resilience? Lessons learned and ways forward. Erkunde 67(1). 5-18.

Keynes, John Maynard. 1937. The general theory of employment. Quarterly Journal of Economics 51(2). 209-223.

Knight, Frank Hyneman. 1921. Risk, uncertainty and profit. Boston: Houghton Mifflin Co.

Krosnick, Jon A., Allyson L. Holbrook, Laura Lowe \& Penny S. Visser. 2006. The origins and consequences of democratic citizens' policy agendas: A study of popular concern about global warming. Climate Change 77(1). 7-43.

Lupton, Deborah. 1999. Risk. London: Routledge.

Methmann, Chris \& Angela Oels. 2015. From 'fearing' to 'empowering' climate refugees: Governing climate-induced migration in the name of resilience. Security Dialogue 46(1). 51-68.

Nash, Sarah L. 2017. From Cancun to Paris: An era of policy making on climate change and migration. Global Policy 9(1). 53-63.

Painter, James. 2013. Climate change in the media: Reporting risk and uncertainty. London: Tauris.

Partington, Alan, Alison Duguid \& Charlotte Taylor. 2013. Patterns and meanings in discourse. Theory and practice in corpus-assisted discourse studies. Amsterdam: John Benjamins.

Russo, Katherine E. 2018. The evaluation of risk in institutional and newspaper discourse: The case of climate change and migration. Naples: Editoriale scientifica.

Schäfer, Mike S., Jurgen Scheffran \& Penniket Logan. 2016. Securitization of media reporting on climate change? A cross-national analysis in nine countries. Security Dialogue 47(1). 76-96.

Stubbs, Michael. 1996. Text and corpus analysis: Computer assisted studies of Language and culture. Oxford: Blackwell.

Warner, Jeroen \& Ingrid Boas. 2017. Securitisation of climate change: The risk of exaggeration. Ambiente \& Sociedade 20(3). 203-224.

Warner, Koko. 2012. Human migration and displacement in the context of adaptation to climate change: The Cancun adaptation framework and potential for future action. Environment and Planning C: Government and Policy 30(6). 1061-1077.

Weingart, Peter, Anita Engels \& Petra Pansegrau. 2000. Risks of communication: Discourses on climate change in science, politics, and the mass media. Public Understanding of Science 9(3). 261-283. 
Zinn, Jens O. \& Marcus Müller. 2021. Understanding discourse and language of risk. Journal of Risk Research. https://doi.org/10.1080/13669877.2021.2020883.

Zinn, Jens O. \& Peter Taylor-Gooby. 2006. Risk as an inter-disciplinary research area. In Peter Taylor-Gooby \& Jens 0. Zinn (eds.), Risk in social science, 20-53. Oxford: Oxford University Press.

\section{Bionotes}

Cinzia Bevitori

Department of Interpreting and Translation, Alma Mater University of Bologna, Forli, Italy cinzia.bevitori@unibo.it

https://orcid.org/0000-0002-1288-4371

Cinzia Bevitori is Associate Professor of English Language and Linguistics at the University of Bologna. Her research interests include corpus linguistics, critical discourse studies, corpusassisted discourse studies, and Systemic Functional Linguistics, focussing in particular on political and news discourse. Her book-length publication is Representations of Climate Change. News and Opinion Discourse in UK and US quality press. (2010, Bononia University Press).

\section{Jane Helen Johnson}

Department of Modern Languages, Literatures and Cultures, Alma Mater University of Bologna, Bologna, Italy

janehelen.johnson@unibo.it

https://orcid.org/0000-0001-5094-418X

Jane Helen Johnson has an MA in Translation Studies from the University of Birmingham and is currently Researcher at the University of Bologna. Her research interests include corpus linguistics, discourse studies, corpus stylistics and translation. 